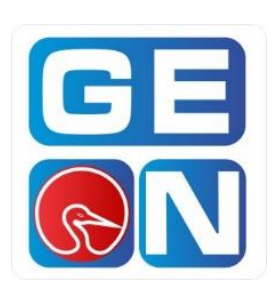

Revista GEON (Gestión, Organizaciones y Negocios.) ISSN: 2346-3910 en línea

revistageon@unillanos.edu.co

Universidad de los Llanos

Colombia

Torres-Flórez, Dagoberto ${ }^{\mathrm{i}}$.

Siete pasos para hacer una selección de personal que le aporte valor a la organización

Revista GEON, Vol. 5, No. 2, 2018

Pág. 4-7

Disponible en: https://doi.org/10.22579/23463910.80

${ }^{\mathrm{i}}$ https://orcid.org/0000-0002-7925-3005

Esta publicación se encuentra bajo licencia: Creative Commons

Reconocimiento-

NoComercial-

SinObraDerivada

4.0 Internacional
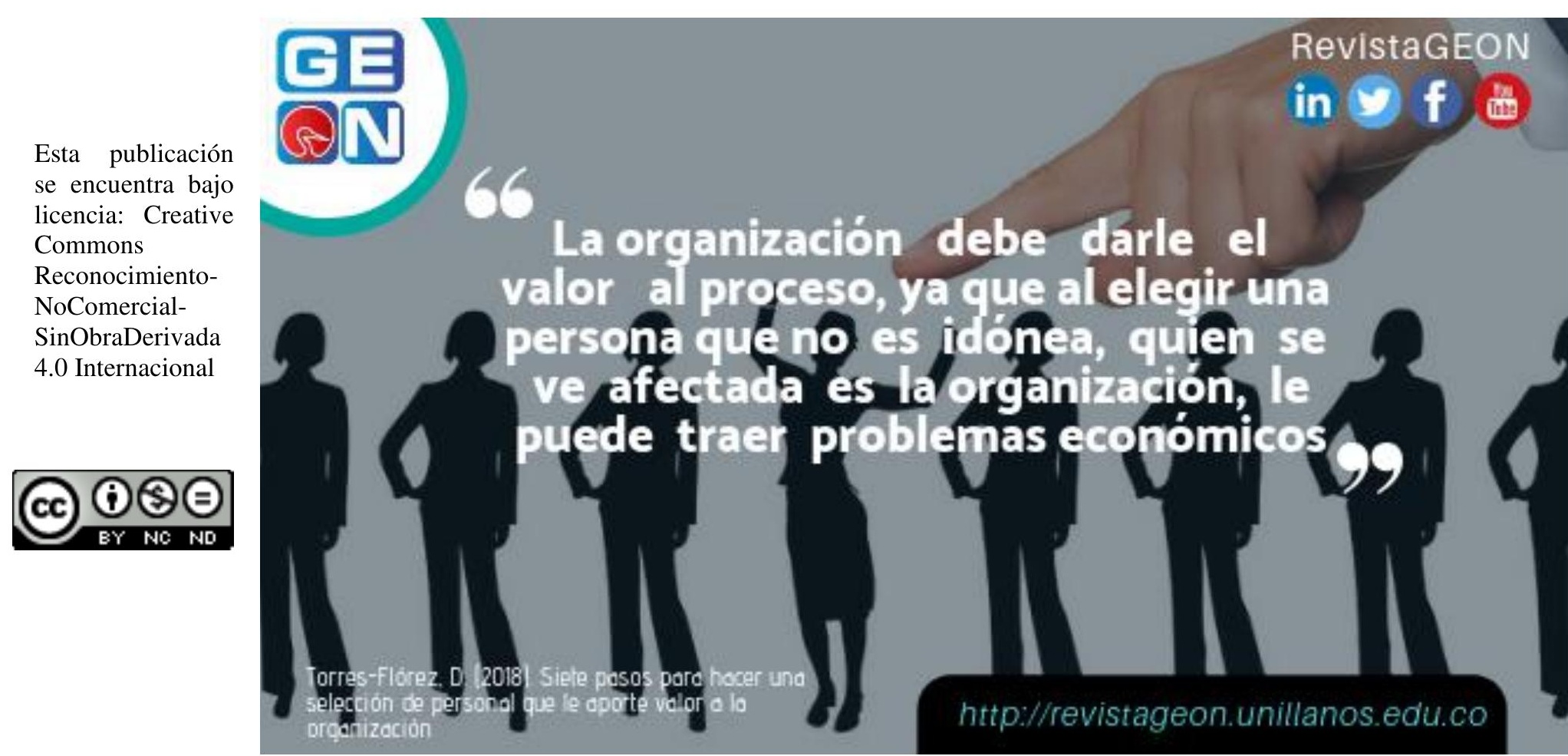


\title{
Siete pasos para hacer una selección de personal que le aporte valor a la organización
}

\section{Seven steps to make a selection of personnel that will add value to the organization}

\author{
Dagoberto Torres-Flórez \\ dtorres@unillanos.edu.co
}

Phd (c) Ciencias Económicas y administrativas, Colombia, Universidad de los Llanos, Líder grupo de investigación GYDO, @ dagoto

Revista GEON Vol. 5 No 2 julio - diciembre 2018 ISSN 2346-3910 en línea http://revistageon.unillanos.edu.co/index.php/geon/article/view/80

\section{Resumen Editorial}

De las situaciones particulares a las que se enfrentan las empresas son cuando deben elegir al personal idóneo para un puesto de trabajo, en especial las pymes que por sus condiciones en ocasiones limitadas de recursos no cuentan con los elementos necesarios para hacer una adecuada selección. Por esta razón se invita a la innovación en la forma en cómo se escoge a la persona alejándose un poco de lo tradicional.

Palabras clave: Selección de personal, gestión humana, estrategia de valor

\section{Abstract}

The particular situations that companies face are when they must choose the right personnel for a job, especially SMEs that, due to their sometimes-limited resources, do not have the necessary elements to make an adequate selection. That is why innovation is invited in the way the person is chosen, moving away from the traditional.

Keywords: Personnel selection, human management, value strategy 


\section{Introducción.}

Al realizar la selección del personal es importante que la organización defina la descripción y análisis de cargo (DyA) a buscar o que se encuentra vacante, en este documento debe definir unos elementos mínimos como nombre del puesto, posición, funciones, tareas o atribuciones y la periodicidad en la que se harán las respectivas como parte de la descripción, ya en cuestión de análisis que se debe hacer después de haber descrito el cargo, se sugiere determinar qué requisitos intelectuales requiere la persona en formación, experiencia y aquellas habilidades (soft skill and hard skill) o competencias, luego indicar que requisitos físicos necesita, que responsabilidades va a tener respecto a recursos o procesos y como son las condiciones y ambientes del puesto de trabajo que nos permita conocer el riesgo laboral al que se enfrentará el nuevo colaborador, para aportar a otros procesos es importante que la empresa cuenta con un modelo de descripción y análisis de cargo para todos los puestos de trabajo y esto le permitirá hacer la gestión humana más eficiente.

Luego es importante hacer una buena convocatoria sea interna o externa que permita tener una cantidad significativa de posibilidades para el proceso, en esto se sugiere utilizar redes de contacto y realizar una redacción concreta y real de los elementos que se buscan coherentes con la DyA determinada para el puesto, así atraer candidatos potenciales y capaces de ocupar los cargos en la organización (Chiavenato, 2009).
En muchas situaciones las pymes tratan de realizar la búsqueda lo más rápido posible, sin embargo, se le recomienda tomarse el tiempo necesario, pues si se elige una persona de afán podría no funcionar y un tiempo cercano estar realizando otro proceso de selección, es ahí donde gestión humana contribuye a que las personas que integran las organizaciones sean importantes en el logro de los objetivos organizacionales (Reyes, 2015), por ello la importancia que se le debe dar al proceso de reclutamiento ya que de este depende que lleguen candidatos idóneos para el puesto de trabajo (Torres-Flórez, Pérez, \& Vanegas, 2017)..

\section{Desarrollo.}

Al momento de tener las hojas de vida o solicitud de empleo y tener una cantidad de suficiente que le permita hacer un proceso de selección efectivo, es necesario que planee que actividades realizará en pro de encontrar un candidato idóneo para el trabajo, para ello es necesario alejarse un poco de lo tradicional, hoy en día a través de Internet existen muchos sitios con pautas para que los candidatos sepan cómo enfrentarse a una entrevista, que poner en la hoja de vida, como vestirse, como actuar, esto convierte en un reto importante para quien debe hacer la tarea de escoger a la persona idónea para esas labores. Por ello se invita a innovar a realizar actividades o situaciones que busquen competencias en las personas y que estas sean coherentes para ello se plantean una serie de siete pasos para un buen proceso. 
Paso 1. Lo primero que debe hacer es revisar las hojas de vida si son coherentes con el anuncio (la importancia de redactar un buen anuncio coherente con la DyA del cargo), esto se debe a que en ocasiones personas presentan su hoja de vida a muchas convocatorias sin revisar si cumplen el perfil.

Paso 2. Se debe encontrar si los principios y valores de la persona son coherentes con la filosofía de la organización, para ello se sugiere definir la relevancia de estos e identificar si la persona cuenta con algunos de ellos. Elegir una persona que sea muy buena para el puesto de trabajo pero que no viva la filosofía de la empresa es muy difícil que le aporte a su estrategia de valor.

Paso 3. Aquí se sugiere que el encargado del proceso tenga claro el perfil de cargo buscado y establecer que elementos son los más relevantes para encontrar esa persona idónea, ya que es complicado encontrar una persona que se adapte totalmente al perfil, aquí se puede reflexionar sobre qué elementos podría adquirir el nuevo colaborador en el proceso de entrenamiento (inducción y capacitación) y poder definir las competencias que realmente debe traer ya adquiridas (García, Hierro, \& Jiménez, 2001).

Paso 4. Debe definir en qué forma hará la selección, para ello lo puede hacer a través de filtro donde cada actividad va descartando candidatos o acumulado donde cada actividad otorga un número de puntos y al final se elegirá entre las dos personas con mayor puntuación
Paso 5. Se recomienda planear actividades en las que usted pueda buscar conocimientos, habilidades y actitudes, esto lo volverá más efectivo y celero en el proceso, además también se le recomienda, es importante tener en cuenta que una actividad sencilla y planeada le puede brindar mayor información al seleccionar las personas.

Paso 6. Es importante luego de las actividades termine con dos posibles candidatos esto le permitirá analizar de las dos personas, sus resultados en las pruebas, verificar sus referencias o documentos necesarios y poder tomar una decisión con alto grado de acierto y puede brindar información valiosa para emitir un pronóstico acerca de los candidatos (López, 1999).

Paso 7. Con la información anterior defina una entrevista final de decisión, ya que esta es la técnica más utilizada, de uso es universal entre empresas latinoamericanas (Maldonado, 2013), la cual se realizará entre dos directivos (se sugiere el jefe inmediato y la gerencia) y ahí con unas preguntas claves de parte de los entrevistadores tomar la decisión final de cuál es el candidato idóneo.

\section{Conclusiones.}

Es importante considerar que la organización debe darle el valor al proceso, ya que al elegir una persona que no es idónea, quien se ve afectada es la organización, le puede traer problemas económicos (Montes \& Gonzales, 2006), para ello es importante invertir los recursos necesarios, el tiempo adecuado e innovar en las distintas actividades para poder encontrar a ese nuevo colaborador 
que le aportará desde su puesto de trabajo valor agregado a la estrategia de la organización.

\section{Referencias.}

Chiavenato, I. (2009). Gestión del Talento Humano. México: Mc Graw Hill.

García, M., Hierro, E., \& Jiménez, J. (2001). Selección de personal, sistema integrado. ESIC.

López, J. (1999). La Selección de Personal.

Maldonado, R. (2013). Entrevista laboral y selección de personal.

Montes, A., \& Gonzales, P. (2006). Selección de personal, la búsqueda del candidato adecuado. ideas propias.

Reyes, D. (2015). Gestión de recursos humanos, importancia y objetivos. Escuela de organización industrial. Obtenido de Escuela de organización industrial: http://www.eoi.es/blogs/mintecon/2015/ 05/04/gestion-de-recursos-humanosimportancia-y-objetivos/

Torres-Flórez, D., Pérez, A., \& Vanegas, J. (2017). Reclutamiento y selección de personal en los hospitales de Villavicencio - Colombia. Encuentro de la comunidad académica de las facultades de Administración y Escuelas de Negocio ASCOLFA, 39-53. Obtenido de http://www.ascolfa.edu.co/web/archivos/ libros/LIBRO_DIGITAL_PONENCIAS _2017.pdf 